OPEN ACCESS

Edited by:

Alexander Steinkasserer, University Hospital Erlangen, Germany

Reviewed by:

Kai Hildner,

University Hospital Erlangen, Germany Stefania Canè,

University of Verona, Italy

*Correspondence:

Manfred B. Lutz

m.lutz@vim.uni-wuerzburg.de

Specialty section:

This article was submitted to Immunological Tolerance and Regulation,

a section of the journa

Frontiers in Immunology

Received: 03 May 2021 Accepted: 15 June 2021

Published: 25 June 2021

Citation:

Thomann AS, Schneider T, Cyran L, Eckert IN, Kerstan A and Lutz MB (2021) Conversion of Anergic T Cells Into Foxp3 $1 L-10^{+}$Regulatory $T$ Cells by a Second Antigen Stimulus In Vivo.

Front. Immunol. 12:704578.

doi: 10.3389/fimmu.2021.704578

\section{Conversion of Anergic T Cells Into Foxp3- IL-10+ Regulatory T Cells by a Second Antigen Stimulus In Vivo}

\author{
Anna Sophie Thomann ${ }^{1}$, Theresa Schneider ${ }^{1}$, Laura Cyran ${ }^{1}$, Ina Nathalie Eckert ${ }^{1}$, \\ Andreas Kerstan ${ }^{2}$ and Manfred B. Lutz ${ }^{1 *}$ \\ ${ }^{1}$ Institute for Virology and Immunobiology, University of Würzburg, Würzburg, Germany, ${ }^{2}$ Department of Dermatology, \\ Venereology and Allergology, University Hospital Würzburg, Würzburg, Germany
}

$\mathrm{T}$ cell anergy is a common mechanism of $\mathrm{T}$ cell tolerance. However, although anergic $\mathrm{T}$ cells are retained for longer time periods in their hosts, they remain functionally passive. Here, we describe the induction of anergic $\mathrm{CD} 4^{+} \mathrm{T}$ cells in vivo by intravenous application of high doses of antigen and their subsequent conversion into suppressive Foxp3 ${ }^{-} \mathrm{IL}_{-10^{+}}$ Tr1 cells but not Foxp3 ${ }^{+}$Tregs. We describe the kinetics of up-regulation of several memory-, anergy- and suppression-related markers such as CD44, CD73, FR4, CD25, CD28, PD-1, Egr-2, Foxp3 and CTLA-4 in this process. The conversion into suppressive Tr1 cells correlates with the transient intracellular CTLA-4 expression and required the restimulation of anergic cells in a short-term time window. Restimulation after longer time periods, when CTLA- 4 is down-regulated again retains the anergic state but does not lead to the induction of suppressor function. Our data require further functional investigations but at this stage may suggest a role for anergic T cells as a circulating pool of passive cells that may be re-activated into $\operatorname{Tr} 1$ cells upon short-term restimulation with high and systemic doses of antigen. It is tentative to speculate that such a scenario may represent cases of allergen responses in non-allergic individuals.

Keywords: $\mathrm{T}$ cells, anergy, Tr1, conversion, in vivo

\section{INTRODUCTION}

$\mathrm{T}$ cell tolerance mechanisms include the induction of $\mathrm{T}$ cell anergy, $\mathrm{T}$ cell deletion and regulatory $\mathrm{T}$ cell (Treg) functions. Although the molecular details, how anergy is induced and maintained, are increasingly understood $(1,2)$, anergy is perceived as a passive state with no function. A functional or active role for anergic $\mathrm{T}$ cells in tolerance has not been defined. The usefulness to maintain anergic $\mathrm{T}$ cells over long periods in vivo is unclear.

Anergy was discovered with $\mathrm{CD} 4^{+} \mathrm{Th} 1 \mathrm{~T}$ cell clones that were stimulated with only via $\mathrm{CD} 3$ antibodies (signal 1 only) without co-stimulation and defined as functional unresponsiveness to further stimulation despite intact antigen presentation by MHC/peptide (signal 1) and full costimulation via CD80/CD86 (signal 2) $(3,4)$. Most experimental settings to induce $\mathrm{T}$ cell anergy in vitro, reported defective IL-2 production and impaired proliferation upon TCR restimulation with or without CD28 costimulation (4-6). This so-called in vitro clonal T cell anergy could be reverted to proliferation by addition of high doses of IL-2 since anergic T cell clones 
highly express CD25 receptors (4). In contrast, IL-2 injection could not restore $\mathrm{T}$ cell proliferation in vivo (4). Mitogens that circumvent TCR-signalling such as combinations of phorbol 12myristate 13-acetate (PMA) together with a calcium ionophore ionomycin have also been documented to revert $\mathrm{T}$ cell anergy (4).

In all cases, anergy, is a passive state that does not fulfill any active tolerogenic role. Therefore, it remains elusive why anergic $\mathrm{T}$ cells are maintained for weeks without obvious further function. Maintaining such $\mathrm{T}$ cells with unwanted antigen specificity may represent a pool of cells that harbours the potential risk for conversion into autoimmunity-mediating effectors after re-activation $(7,8)$. There is experimental evidence that anergic $\mathrm{T}$ cells can produce immuno-suppressive IL-10 (9-11). However, the physiological stimuli or cell types and mechanistic details that lead to $\mathrm{T}$ cell anergy in vivo are not well understood. Tolerogenic dendritic cells (DC) producing IL-10 may induce regulatory function in anergic $\mathrm{T}$ cells. In vitro exposure or injection of immature or semi-mature DC maturation stages of different DC subsets have been shown to induce either $\mathrm{T}$ cell anergy or the development into different subsets of Tregs, such as induced Foxp $3^{+}$Tregs (iTregs) or Foxp3- $3^{-}-10^{+}$type 1 regulatory $(\operatorname{Tr} 1)$ cells $(12,13)$.

In mice, a single intravenous injection of soluble peptide, superantigen or a neo-self-antigen expression induced $\mathrm{T}$ cell anergy (14-18). Subsequent IL-10 production by these anergic $\mathrm{T}$ cells has been observed after several intravenous injections of peptides that were captured and presented most likely by immature DCs (19). Anergic $\mathrm{CD}^{+} \mathrm{T}$ cells also appear in normal healthy mice. They can be identified by the surface marker profile CD $44^{\text {high }} \mathrm{CD} 73^{\text {high }}$ folate receptor $4(\mathrm{FR} 4)^{\text {high }}$ and could convert into Foxp $3^{+}$Tregs after adoptive transfer where they prevented autoimmunity $(20,21)$.

Previously, we addressed the possibility for a conversion of anergic $\mathrm{T}$ cells into Foxp $3^{-} \mathrm{Tr} 1$ cells in vitro. Here, our in vivo data confirm now the in vitro observations of the transient induction of CTLA-4 expression after high dose i.v. OVA injection. However, only after two short-term interval injections, the cells acquire a Foxp $3^{-}$IL- $10^{+} \operatorname{Tr} 1$ phenotype and regulatory function. Together, these data suggest that anergic $\mathrm{T}$ cells can represent a precursor for $\operatorname{Tr} 1$ cells.

\section{MATERIALS AND METHODS}

\section{Mice}

C57BL/6, B6.OT-II.Rag1 ${ }^{-/}$, BALB/c and DO11.10 mice were bred in the animal facilities of the Institute of Virology and Immunobiology at the University of Würzburg under specific pathogen-free conditions or purchased from Charles River. The IL-10- $\beta$-Lactamase reporter mouse strain ITIB (22) was kindly provided by Dr. Ulrike Protzer (Technical University Munich). ITIB mice were crossed with B6.OT-II.Rag1 $1^{-/-}$mice and the resulting F1 generation was further crossed to obtain ITIB.OTII and ITIB.OT-II.Rag1 $1^{-/-}$mice. Animal experiments were performed after approval and under control of the local authorities (Regierung von Unterfranken, AZ 52/14).

\section{CCF4-Substrate Loading and Antibody Staining}

For CCF4-substrate loading, $1 \times 10^{6}$ cells were resuspended in R10 medium (RPMI 1640 (Sigma) with 10\% heat-inactivated FCS (Gibco), $100 \mu \mathrm{g} / \mathrm{ml}$ Penicillin-Streptomycin, $2 \mathrm{mM}$ L-glutamine and $50 \mu \mathrm{M} 2$-mercaptoethanol (all Sigma)) containing $1.3 \mu \mathrm{M}$ CCF solution (Invitrogen) and 3.6 $\mu \mathrm{M}$ Probenecid (Sigma) and incubated for $90 \mathrm{~min}$ at RT in the dark. After incubation, the cells were washed with FACS buffer and subsequently stained in FACS buffer containing 10\% 2.4G2 hybridoma cell line supernatant (anti-Fc $\gamma$-RII/III, as Fc block). Surface staining was performed with antibodies to CD25 (PC61), CD28 (E18), CD4 (GK1.5), CD44 (IM7), CD73 (TY/11.8), FR4 (12A5), PD-1 (RMP1-30), Vo2 (B20.1), DO11.10 TCR clonotype (KJ1-26) (all BioLegend) and V $35.1,5.2$ (MR9-4) (BD Biosciences). In the case of staining with biotinylated antibodies, surface staining was followed by a second incubation with fluorophoreconjugated streptavidin. Subsequently, the cells were fixed with $1 \%$ formaldehyde and analysed on a BD LSR II flow cytometer.

\section{Intracellular and Intranuclear Staining}

Cells were stimulated in R10 medium containing $10 \mathrm{ng} / \mathrm{ml}$ PMA, $1 \mu \mathrm{g} / \mathrm{ml}$ Ionomycin and $5 \mu \mathrm{g} / \mathrm{ml}$ Brefeldin A (all Sigma) for 4 hours at $37^{\circ} \mathrm{C}$. After CCF4-substrate loading and surface staining, the cells were fixed and permeabilized using the Foxp3/Transcription Factor Fixation/Permeabilization Concentrate and Diluent (eBioscience) according to manufacturer's instructions. Intracellular and intranuclear staining was performed in 1x Permeabilization Buffer (eBioscience) using the following antibodies: CTLA-4 (UC10-4B9), Foxp3 (150D), IFN- $\gamma$ (XMG1.2), Ki-67 (16A8) (all BioLegend) and Egr-2 (erongr2, eBioscience).

\section{Adoptive Transfers and Immunizations}

Adoptive $\mathrm{T}$ cell transfer was performed by i.v. injection of 1$2 \times 10^{7}$ bulk lymph node and spleen cells from DO11.10 or (ITIB.) OT-II mice or $4.5-7 \times 10^{6}$ (ITIB.)OT-II.Rag1 ${ }^{-/-}$cells into BALB/c or $\mathrm{C} 57 \mathrm{BL} / 6$ recipient mice, respectively. One day later, anergy was induced by injection of $275 \mu$ OVA $_{327-399}$ peptide (China Peptides) or 400-1000 $\mu \mathrm{g}$ OVA protein (Profos, Endograde, endotoxin-free). Control mice received PBS injections instead of OVA. For $\operatorname{Tr} 1$ conversion experiments, the mice received a second OVA injections 3 days (short interval) or 11 days (long interval) after the first one.

\section{Ex Vivo Proliferation and Suppression Assays}

TCR transgenic DO11.10 T cell transfers were performed as indicated. One day later animals were injected once or a second time with OVA using the same dose and route after 3 days (short interval) or 11 days (long interval) or PBS. For anergy determination, 3 days after the last OVA injection erythrocytelysed spleen cells were labelled with CFSE and restimulated with $100 \mathrm{U} / \mathrm{ml}$ mouse IL-2 (Peprotech), anti-CD3 alone or anti-CD3 
and anti-CD28 antibodies $(2.5 \mu \mathrm{g} / \mathrm{ml}$ each, soluble, LEAF quality, BioLegend) or $10 \mu \mathrm{M}$ OVA peptide. FACS analysis for CD4, KJ126 and CFSE of spleen cells was performed after 5 days to analyse the proliferation history of the DO11.10 T cells. For determination of suppression in vivo, 5 days after the last OVA injection, erythrocyte-lysed spleen cells were directly FACS analysed for their frequency of $\mathrm{CD} 4^{+} \mathrm{KJ} 1-26^{+}$and further for the intracellular CTLA-4 or intranuclear Foxp 3 among them. For determination of suppression in vitro, 5 days after the last OVA injection, erythrocyte-lysed spleen cells were enriched for $\mathrm{CD}^{+}$ cells by magnetic cell separation (MACS) according to the manufacturer's instructions. To test their suppressor capacity these $\mathrm{CD}^{+}$cells were added to CFSE-labelled MACS-enriched $\mathrm{CD}^{+} \mathrm{T}$ cells from BALB/c lymph nodes stimulated with antiCD3 antibodies and irradiated spleen APCs as we performed before (23). After 5 days proliferation was detected as CFSE dilution measured by FACS.

\section{Statistical Analysis}

Data are presented as mean \pm SEM or SD as indicated in the figure legend. Unpaired t-tests were used for comparison of cytokine production after first and second OVA injection. The statistical differences between more than two groups were calculated using one-way ANOVA with Tukey's test for multiple comparisons. All statistical analyses were performed using PRISM 7 (GraphPad).

\section{RESULTS}

\section{Induction of T Cell Anergy Markers on Naïve CD4 ${ }^{+}$OT-II Cells After OVA Peptide or Protein Injection}

Anergic T cells can be induced in vivo by intravenous injection of high dose antigen (14-16) but a characteristic phenotype of anergic $\mathrm{T}$ cells is still controversially discussed due to the lack of specific surface markers. A subset of anergic $\mathrm{T}$ cells present in steady state healthy mice express CD44, CD73 and FR4 (20). Furthermore, CTLA-4 have been shown to be required for anergy induction and maintenance (24). Intracellular CTLA4 (iCTLA-4) detection better reflects its kinetics of total expression (25) since surface levels at a given time point are usually very low due to permanent recycling of the molecule (26, 27). To demonstrate anergy induction we used the TCR transgenic OT-II system. After adoptive transfer, injected OTII cells can be identified by the co-expression of the TCR chain variants $\mathrm{V} \alpha 2$ and $\mathrm{V} \beta 5$ (Figure 1A). We investigated the expression levels of different anergy markers in adoptively transferred T cells upon i.v. injection of high dose antigen in form of either OVA peptide or OVA protein. Transferred OT-II cells contained less than $5 \%$ Foxp $3^{+}$cells, which did not increase upon OVA injection (Figures 1B, C). However, 5 days after OVA injection, OT-II cells co-expressed the surface markers FR4 and CD73 (Figures 1D, E). Furthermore, the cells expressed high levels of CD44 and iCTLA-4 (Figures 1F, G). Comparing the injection of OVA protein versus peptide, there was no difference in the expression of these markers between the two types of antigen. This indicates that following a protocol for anergy induction after injection of high dose antigen in form of both OVA protein and OVA peptide results in the upregulation of typical anergy markers in adoptively transferred OT-II cells. Since early events of the physiological immune response require antigen processing and presentation, we decided to use the whole OVA protein in subsequent experiments.

\section{Kinetics of Anergy Marker Up-Regulation}

In addition to CD44, FR4 and CD73, others have suggested a combination of antibodies against CD7, CD28 and PD-1 to distinguish anergic $\mathrm{T}$ cells from both naïve and activated $\mathrm{T}$ cells (28). Furthermore, the transcription factor Egr-2 has been shown to be required for complete anergy induction (29). We therefore analysed these markers at different time points after OVA injection. 24 hours after OVA protein injection, the transferred OT-II cells upregulated CD25, but later downregulated it to levels of unstimulated cells by day 3 after antigen injection (Figure 2A). CD44, CD28 and PD-1 were upregulated soon after OVA injection but decreased again by day 5 (CD44) or day 3 (CD28, PD-1). However, their expression remained always slightly above the levels of unstimulated cells (Figure 2A). In contrast, CD73 and FR4 continuously increased over time. Surprisingly, the anergy-specific transcription factor Egr-2 also peaked already 24 hours after OVA injection and remained significantly upregulated over the level of control cells. iCTLA-4 was strongly upregulated upon OVA injection and remained at high levels until day 5 similar to the kinetics described in vitro (23). After activation and CD25 upregulation, the cells accumulated in the spleen since we observed the highest frequency of OT-II cells (about $12 \%$ of $\mathrm{CD}^{+} \mathrm{T}$ cells) on day 3 after OVA injection. However, after accumulation, the cells collapsed rapidly again resulting in a frequency of only $2 \%$ of OT-II cells within all $\mathrm{CD} 4^{+} \mathrm{T}$ cells on day 5 (Figure $2 \mathrm{~B}$ ). As expected, the original ratio of about $95 \%$ Foxp $3^{-}$and 5\% Foxp $3^{+}$cells among the transferred OTII bulk population remained stable and did not favour Foxp $3^{+}$cell expansion (Figure 2C). The absolute number of Foxp $3^{+}$cells remained very low and did not increase significantly at any time point after OVA injection (Figure 2D). In contrast, the absolute number of Foxp $3^{-}$cells increased massively at day 3 (Figure 2E). This indicates that almost exclusively the Foxp $3^{-}$population responds to high dose antigen encounter with a massive expansion (Figure 2E). Taken together, adoptively transferred OT-II cells were activated and accumulated in the spleen - but rapidly collapsed as well - after high dose OVA injection associated with the upregulation of anergyassociated surface markers and transcription factors acquiring a Foxp $3^{-} \mathrm{CD}_{4} 4^{+} \mathrm{CD}_{3}{ }^{+} \mathrm{FR} 4^{+} \mathrm{CTLA}-4^{+}$Egr $-2^{+} \mathrm{CD} 25^{-}$phenotype.

\section{Maintenance of Anergic Phenotype After a Second Antigen Injection}

Stimulation of anergic T cells by immature DCs in vitro as well as repetitive administration of antigen in vivo has been shown to convert anergic T cells into IL-10-producing $\operatorname{Tr} 1$ cells $(19,23)$. We hypothesized that a second antigenic stimulus must occur within a short time window after the first injection, in which CTLA-4 is highly expressed on the anergic T cells, to allow for 
A

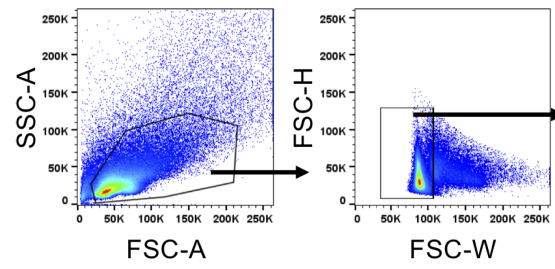

:

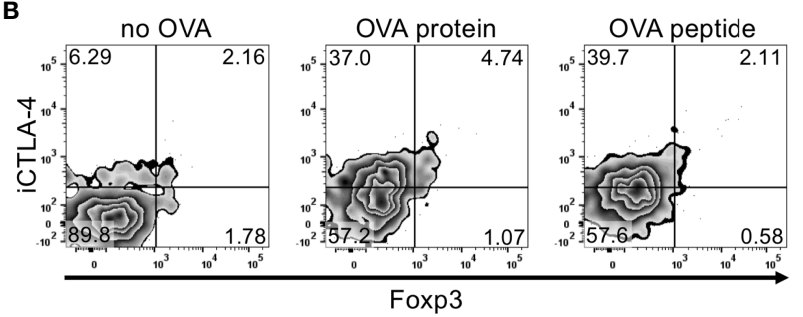

D
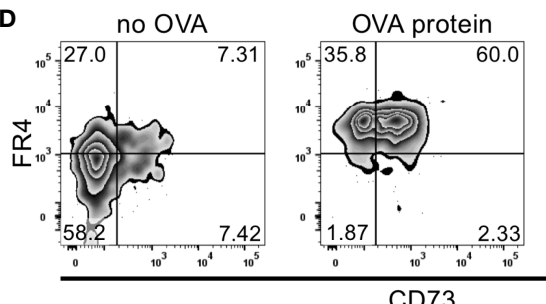

$\mathbf{F}$
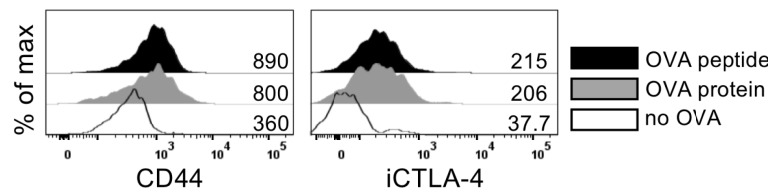

G

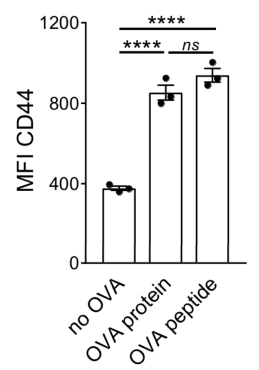

OVA peptide
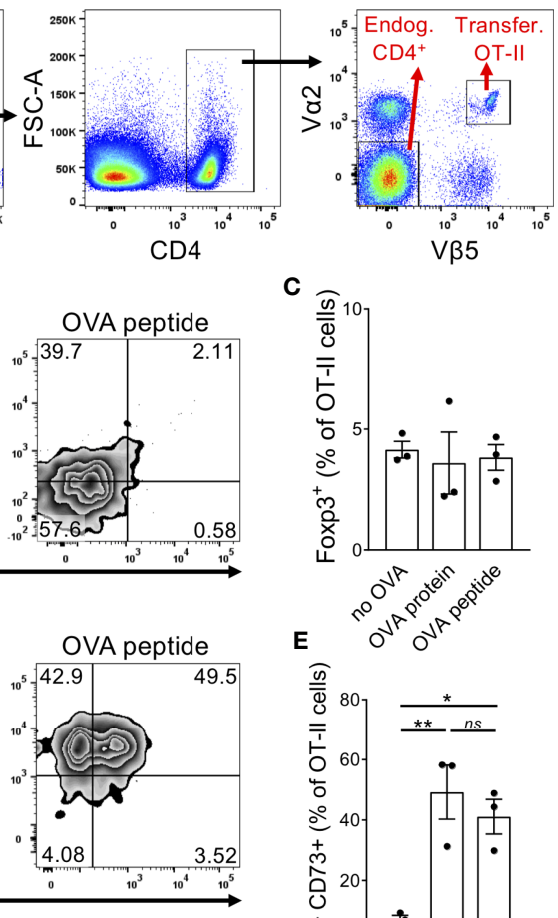

C

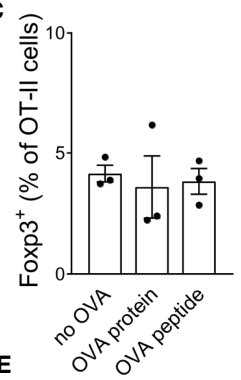

$E$

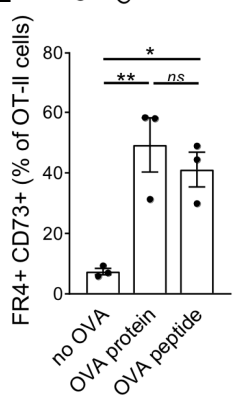

FIGURE 1 | Adoptively transferred naiive T cells upregulate different anergy markers after high dose OVA injection. Transferred OT-II cells isolated from the spleen of recipient mice were tested for expression of different anergy markers 5 days after i.v. OVA $327-339$ peptide or OVA protein injection. (A) Gating strategy. Cells were first

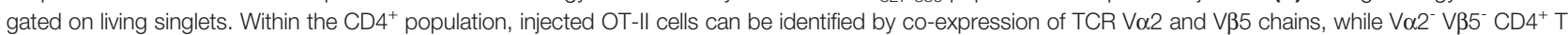
cells were chosen as endogenous control cells. (B) Representative FACS plots show expression of intracellular CTLA-4 (iCTLA-4) and Foxp3 in transferred OT-II cells. (C) Quantification of the frequency of Foxp3+ cells in transferred OT-Il cells. (D) Representative FACS plots show co-expression of FR4 and CD73.

(E) Quantification of the frequency of $\mathrm{FR} 4^{+} \mathrm{CD} 73^{+}$double-positive cells in transferred OT-II cells as mean $\pm \mathrm{SEM}$. (F) Representative histogram overlays show marker expression in transferred OT-II cells from non-injected (white), OVA $327-339$ protein-injected (grey) or OVA peptide-injected (black) mice. Numbers indicate median fluorescence intensities (MFIs). (G) Expression of anergy markers is shown as MFI within OT-Il cells summarized as mean \pm SEM. Dots represent individual mice. ${ }^{*} \mathrm{p}<0.05,{ }^{* *} \mathrm{p}<0.01,{ }^{* \star * *} \mathrm{p}<0.0001$, one-way ANOVA with Tukey post-test. ns, not significant.

conversion into Tr1 cells. Therefore, the mice received a second intravenous OVA injection 3 days after the first one, when the cells had already downregulated CD25 in response to the first injection but expressed high levels of iCTLA-4 (Figure 2A). To investigate whether the cells preferentially convert into Foxp $3^{-}$
Tr1 cells or rather Foxp3 $3^{+}$Tregs, we now transferred OT-IIRag $^{-1-}$ cells, which lack endogenous Foxp $3^{+}$Tregs. Five hours after the second injection, the cells still showed a phenotype similar to those that had received only one antigen stimulus (Figures 3A, B). However, at later time points such as 24 hours 
A
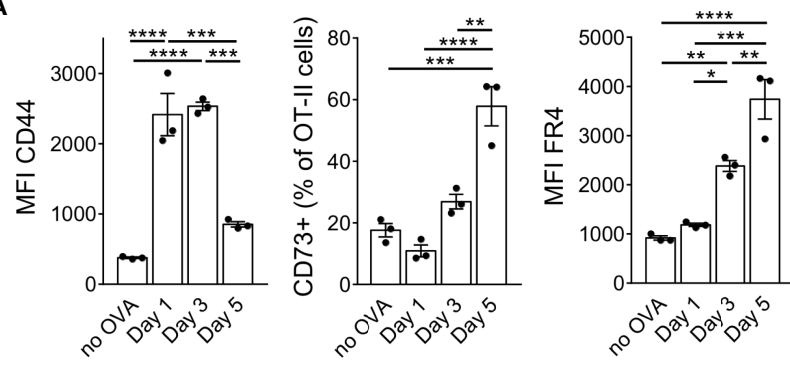

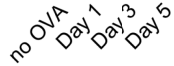
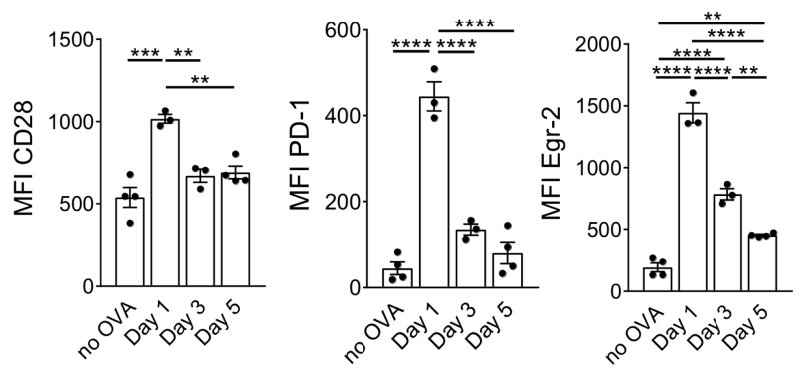

C
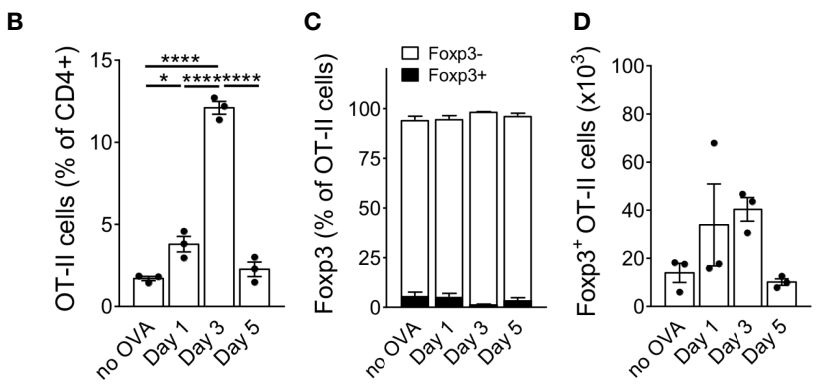
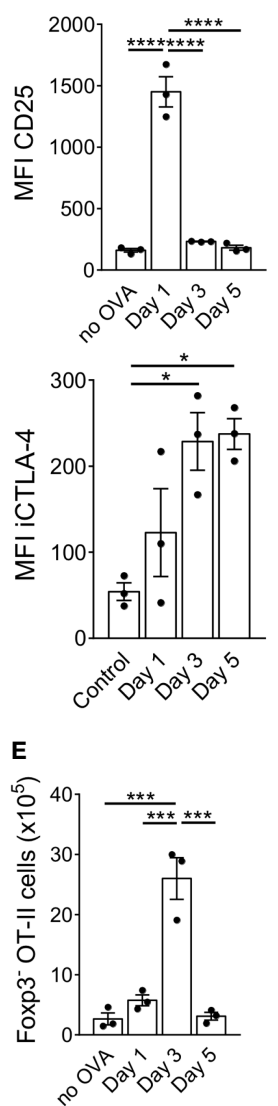

FIGURE 2 | Anergy markers show different kinetics during anergy induction. (A) Expression of anergy markers was analysed in adoptively transferred OT-II cells at different time points after a single OVA injection and is shown as MFI when all cells up-regulated the marker in a uniform manner or as frequency when the population split into positive and negative cells for the marker staining (CD73). (B) Frequency of OT-II cells at indicated time points. (C) Frequency of Foxp3 ${ }^{+}$and Foxp3 ${ }^{-}$cells within the OT-II population at indicated time points. (D) Absolute numbers of Foxp3 ${ }^{+}$and (E) of Foxp3 ${ }^{-}$cells at indicated time points after OVA protein injections. Data is shown as mean \pm SEM. Dots represent individual mice. ${ }^{*} p<0.05,{ }^{* \star} p<0.01,{ }^{\star \star \star} p<0.001,{ }^{\star \star \star \star} p<0.0001$, one-way ANOVA with Tukey post-test.

or 72 hours after the second injection, the cells further upregulated the anergy markers CD73 and FR4 (Figures 3A, B). Other markers such as CD44, CD28, PD-1 or Egr-2 followed kinetics similar to the one observed after only one injection (Figures 3A, B) suggesting the maintenance of the anergic phenotype. Of note, the cells displayed a complete unresponsiveness to upregulate the cell activation marker CD25 at any time point upon the second antigen stimulus further strengthening the anergic state.

\section{Induction of Foxp3- IL-10+ Tr1-Like Cells After a Second Injection of Antigen}

Tr1 cells are mainly characterized by the secretion of high levels of IL-10 in the absence of Foxp3 expression (30). We therefore tested our anergic cells for the expression of these markers after the second OVA injection within short time intervals ranging from $5 \mathrm{~h}$ to $72 \mathrm{~h}$. To measure IL-10 expression, we used T cells derived from OT-II.Rag1 $1^{-/-}$mice crossed with an IL-10- $\beta$ Lactamase reporter mouse strain (ITIB) (22). We did not observe a substantial Foxp $3^{+}$population in the adoptively transferred ITIB.OT-II cells at any time point indicating that anergic $\mathrm{T}$ cells did not convert into Foxp $3^{+}$iTregs in our setting (Figures 4A, B). IL-10 expression was measured using the $\beta$ Lactamase reporter system of the transferred ITIB.OT-II cells. Reporter activity of this enzyme can be detected by using the fluorogenic substrate coumarin-cephalosporin-fluorescein (4)acetoxymethyl (CCF4-AM) (31). After entering the cell, CCF4 emits green light $(520 \mathrm{~nm})$ due to fluorescence resonance energy transfer (FRET) from the coumarin donor to the fluorescein acceptor upon excitation at $409 \mathrm{~nm}$. Enzymatic cleavage of CCF4 by $\beta$-Lactamase, however, interrupts this energy transfer leading to blue emission $(447 \mathrm{~nm})$ instead (31). Therefore, IL-10 expression directly correlates with the frequency of CCF4product $^{+}$cells. $24 \mathrm{~h}$ after the second OVA injection the 
A
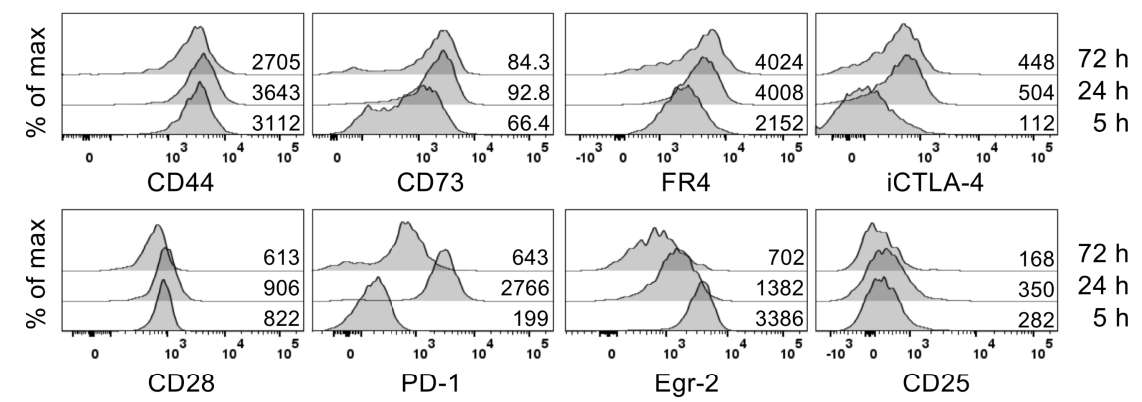

B

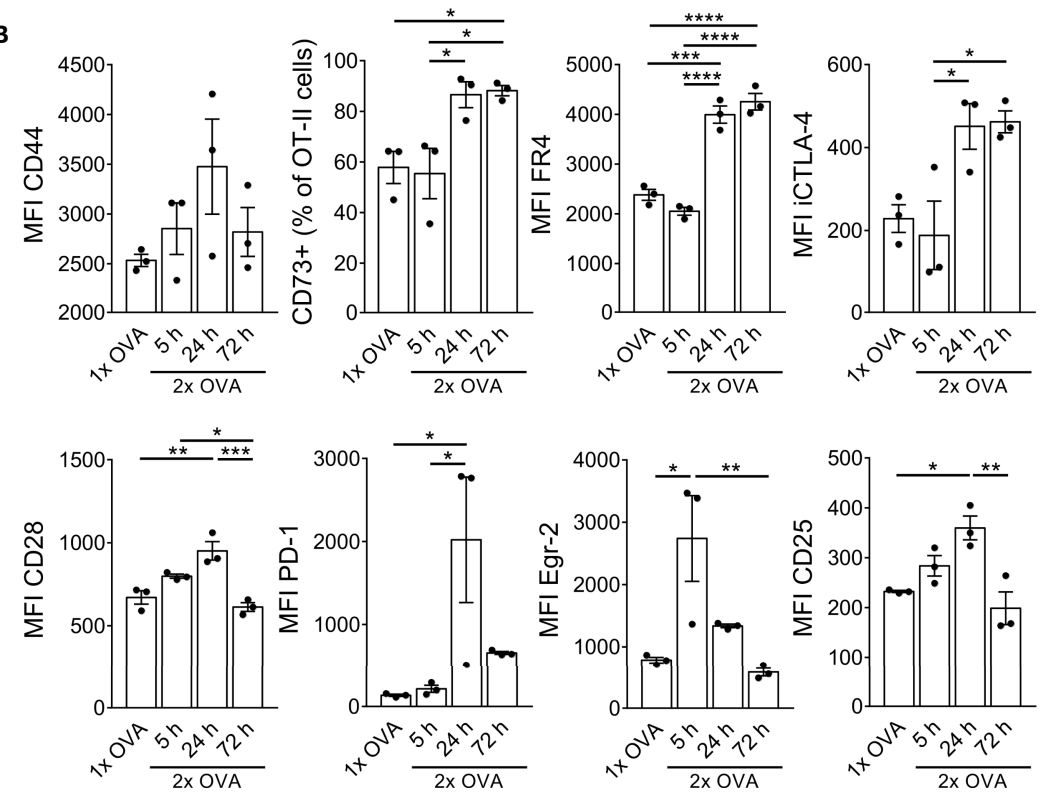

FIGURE 3 | T cells retain their anergic phenotype after a second OVA injection within a short time interval. OT-II.Rag $1^{-/-}$cells were adoptively transferred into C57BL/6 WT recipient mice and received a first i.v. OVA protein injection 1 day after adoptive transfer. A second OVA injection was given 3 days after the first one. 5,24 or 72 hours after the second injection, spleen cells were isolated and stained for indicated surface markers. (A) Representative histograms depict marker expression in OT-II cells 5 hours (bottom), 24 hours (middle) or 72 hours (top) after the second OVA injection. Numbers indicate MFls or frequency of CD73 ${ }^{+}$cells within OT-II cells. (B) Data from A summarized as mean \pm SEM. Dots represent individual mice. ${ }^{\star} p<0.05,{ }^{\star \star} p<0.01$, ${ }^{\star \star \star} p<0.001$, ${ }^{\star \star \star \star} p<0.0001$, one-way ANOVA with Tukey post-test.

frequency of IL- $10^{+}$cells almost reached $20 \%$ as compared to less than $5 \%$ IL- $10^{+}$ITIB.OT-II cells after a single OVA injection (Figures 4C, D).

Taken together, anergic $\mathrm{T}$ cells acquire a Foxp $3^{-}$IL- $10^{+}$ phenotype supporting our hypothesis of conversion into Tr1 cells after a second antigen encounter within a short time interval.

\section{Transient iCTLA-4 Expression and T Cell Anergy Induction After One or Two OVA Injections}

CTLA-4 acts as a negative regulator of T cell responses and is upregulated in both effector and regulatory $\mathrm{T}$ cell subtypes (32) as well as during anergy induction $(23,24)$. We found before in vitro that anergic cells up-regulated CTLA-4 and its high expression was maintained and required for subsequent $\operatorname{Tr} 1$ generation. When the second antigen stimulation occurred during the phase when CTLA-4 was already down-regulated again, the cells remained anergic but failed to become IL- $10^{+} \operatorname{Tr} 1$ cells (23).

Thus we investigated the question also in vivo whether high dose OVA injections would functionally lead to $\operatorname{Tr} 1$ conversion only in a short time frame between the two OVA injections when CTLA-4 is still highly expressed, as opposed to a long-term interval when CTLA-4 is down-regulated. Although we used the OT-II system successfully to study $T$ cell anergy to $\operatorname{Tr} 1$ conversion in vitro (23), the OT-II system did not allow us to follow adoptively transferred and anergized $\mathrm{CD} 4^{+} \mathrm{T}$ cells for longer time periods in vivo. Transferred OT-II cells became partially activated showing the expression of anergy markers and 


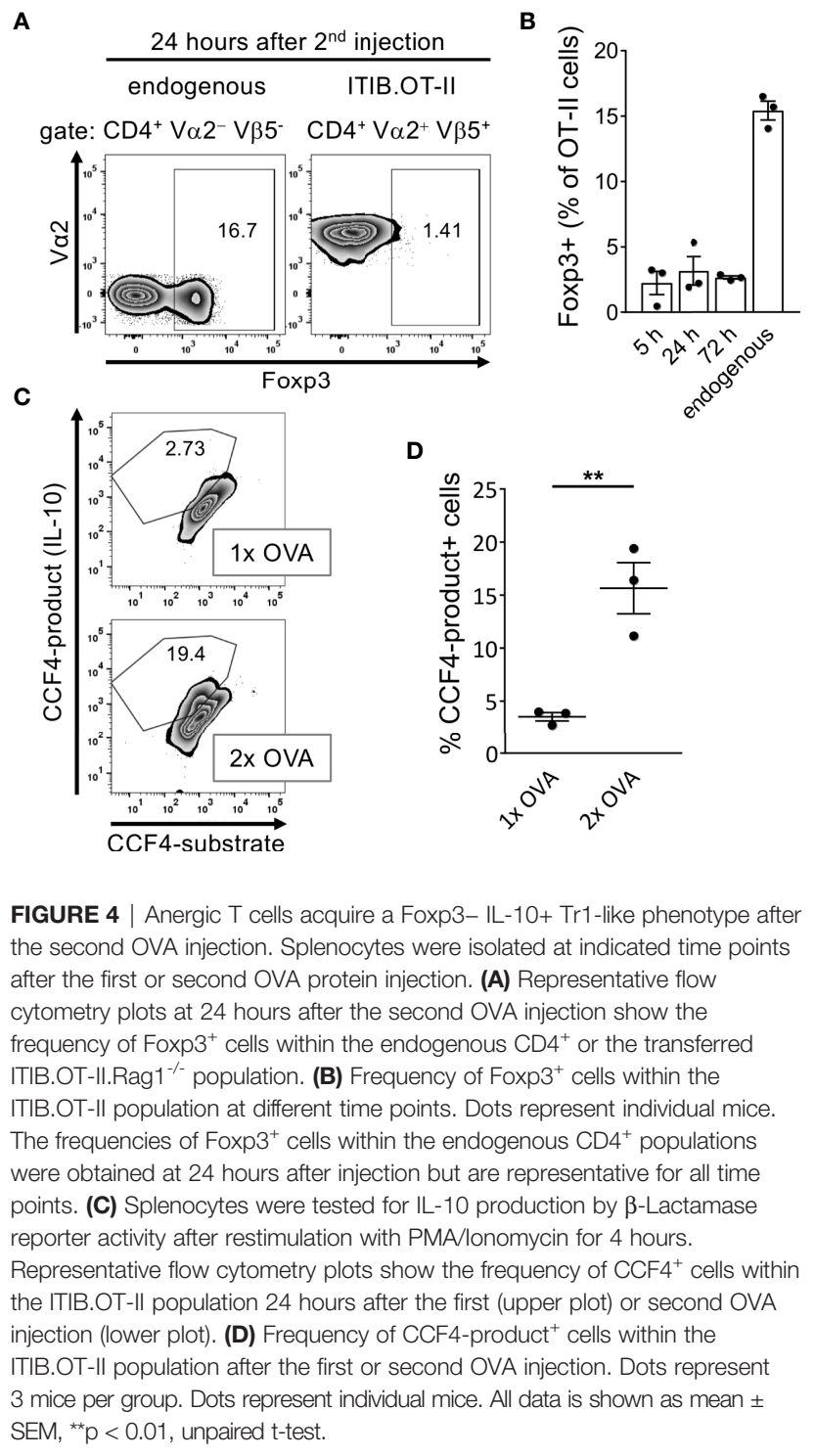

expanded after a single OVA injection but finally disappeared thereafter within 7-10 days (not shown). The mild stimulation by OVA injection in the absence of adjuvants did not allow their survival. Anergic cells undergo deletion during the contraction phase, an accompanying mechanism that has been reported to be associated with T cell anergy induction in vivo (33). In addition, the OT-II system may have other specific deficits. OT-II cells can be activated and polarized as shown by many groups including ourselves (34). However, they did not differentiate into stable memory $\mathrm{T}$ cells, which was in some cases due to peripheral deletion by responses of $\mathrm{V} 5^{+} \mathrm{T}$ cells in $\mathrm{C} 57 \mathrm{BL} / 6$ mice to endogenous superantigen derived from Mtv-9 (35), thus including OT-II cells (36). Here, we found that OT-II cells were unable to develop into a stable anergic phenotype after OVA injection and, after a second injection using a long-term interval, most OT-II cells were deleted.
Since the deletion of OT-II cells during the contraction phase precluded further analyses after the second OVA injection. We observed before in another OVA-specific $\mathrm{CD} 4^{+}$TCR-transgenic system, that adoptively transferred DO11.10 $\mathrm{T}$ cells also contracted after the expansion phase but remained at a stable frequency at least until day 8 after transfer (37). Therefore, and since anergy is a general phenomenon that is not restricted to certain antigens or a specific system of transgenic $\mathrm{T}$ cells, we switched to the DO11.10 system.

Our previous in vitro analysis indicated that generation of anergic and suppressive $\operatorname{Tr} 1$ cells only during short-term restimulation critically depended on high CTLA- 4 expression, while longer intervals failed to do so due to CTLA-4 downregulation (23). When we tested iCTLA-4 expression after high dose OVA injection, we found, similar to our in vitro data and the OT-II system above, a fast but transient up-regulation of iCTLA-4 in adoptively transferred DO11.10 T cells on day 2 to 4 quickly dropping thereafter (Figure 5A).

In addition to upregulation of anergy-related surface markers, in vivo induced anergy is characterized by a defect antigen-specific response to restimulation with OVA or using antibodies directed against $\mathrm{CD} 3$ or both $\mathrm{CD} 3 / \mathrm{CD} 28$ molecules. Other than in vitro, in vivo anergized $\mathrm{T}$ cells do not respond with proliferation on high doses of IL-2 (4). Our data show that a single injection of high dose OVA protein results in functional anergy induction in adoptively transferred DO11.10 T cells in the spleen. We found, that after a single OVA injection DO11.10 transgenic T cells did not respond with proliferation to IL-2, poorly to OVA peptide and much lower than endogenous non-anergized $\mathrm{T}$ cells to stimulation with $\mathrm{CD} 3$ and $\mathrm{CD} 3 / \mathrm{CD} 28$ antibodies (Figures 5B, C). To further test whether a second OVA injection would promote the maintenance of the anergic phenotype, we used a short (3 days) or a long-term interval (11 days) for OVA application. Both protocols revealed a sustained anergic state as observed after a single injection of OVA (Figures 5B, C). Together, these data indicate that high iCTLA-4 expression correlates with the capacity of anergic $\mathrm{T}$ cells to convert into $\operatorname{Tr} 1$ cells, whereas using the long-term interval the anergic $\mathrm{T}$ cells simply remain anergic.

\section{Short-Term but Not Long-Term Interval OVA Injections Favour Induction of CD4 ${ }^{+}$iCTLA $-4^{+}$Foxp3- $\mathrm{T}$ Cells With Suppressor Function}

Next, we analysed whether the DO11.10 T cells expanded, developed into Foxp $3^{+}$or Foxp3 ${ }^{-}$cells and showed regulatory properties. While the short interval led to an increased frequency of splenic DO11.10 T cells, the long-term interval frequency remained almost at the level of control mice (no OVA) (Figure 6A). Additional staining for iCTLA-4 and Foxp3 indicated that the frequencies of $\mathrm{CD}^{+} \mathrm{KJ} .26^{+} \mathrm{Foxp}^{+}$Treg (Figures 6B, C) as well as $\mathrm{CD}^{+}{ }^{+} \mathrm{KJ} 1.26^{+}{ }^{+}$iCTLA $^{-} 4^{+}$Foxp3 $^{-}$cells (Figures 6B, D) were enhanced as compared to not OVA injected controls. However, as predicted, the short-term 
A

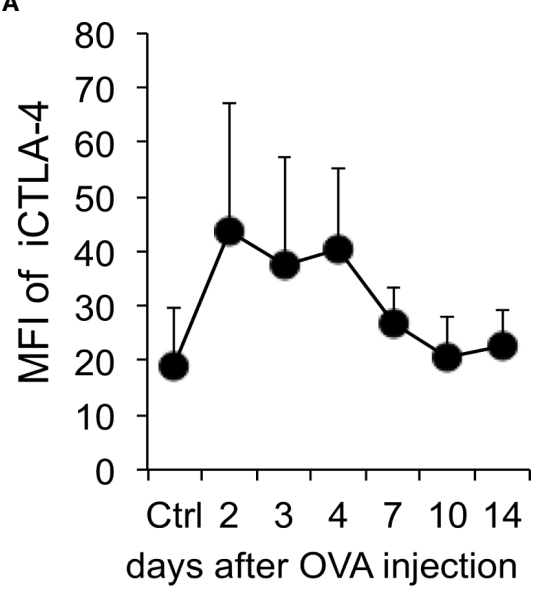

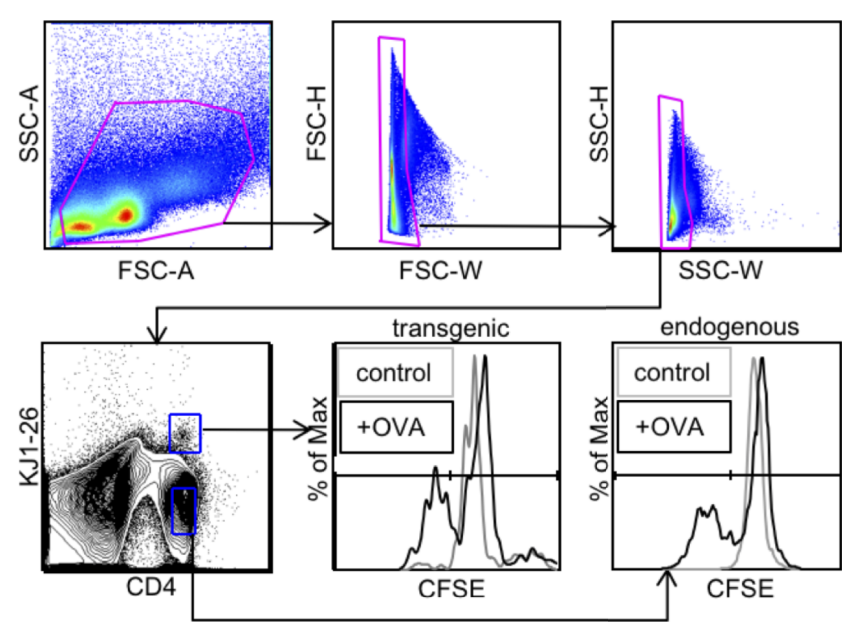

C

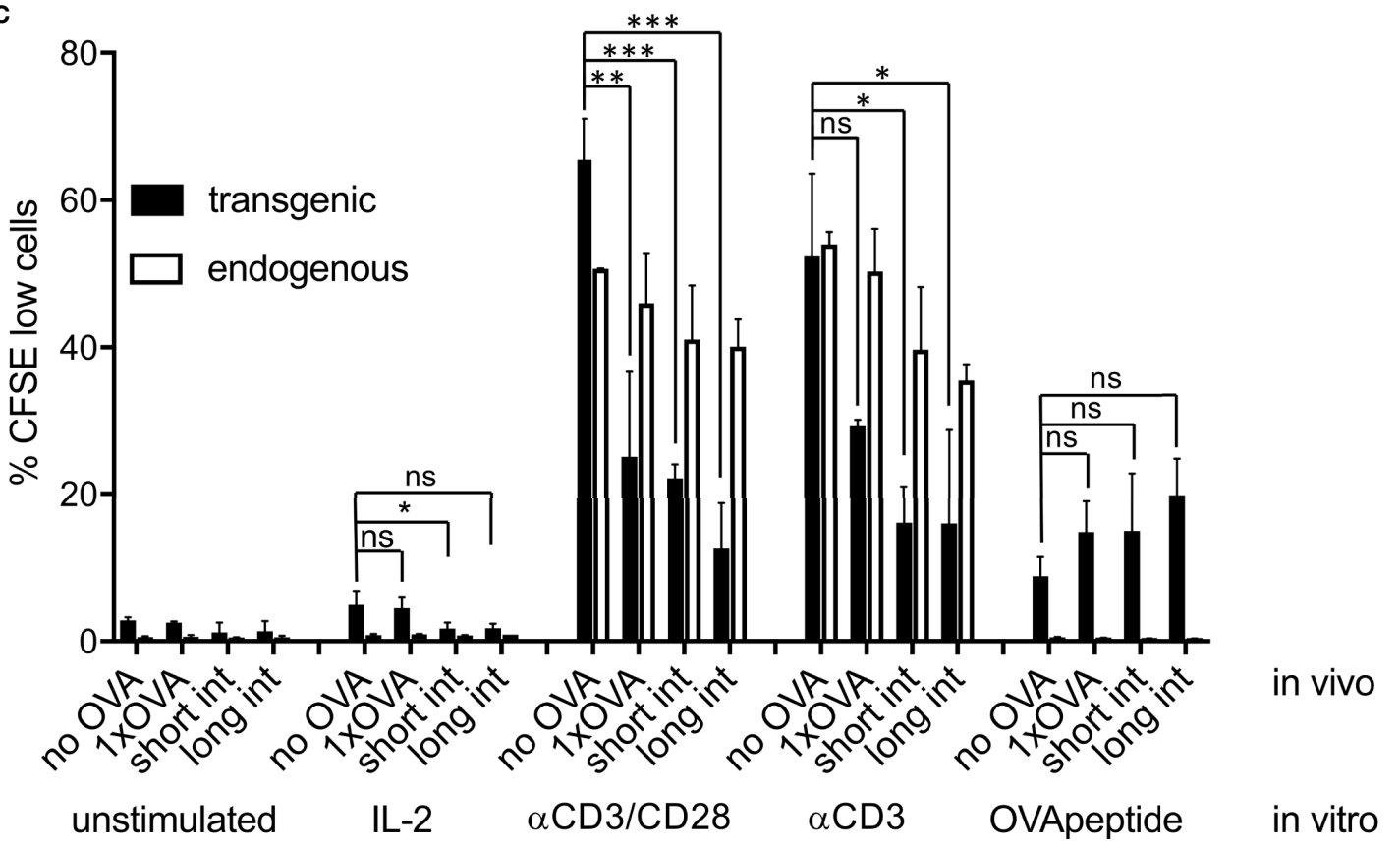

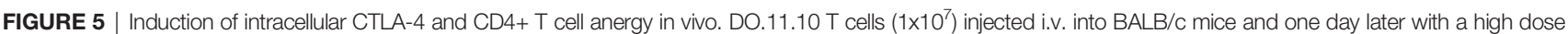
endotoxin-free OVA protein. (A). FACS analysis of $\mathrm{CD4}^{+}, \mathrm{KJ1}^{-26^{+}}$, Foxp3 ${ }^{-}$cells for their iCTLA-4 mean fluorescence intensity (MFI) of spleen cells was performed at the indicated time points. Control mice received DO11.10 cells but remained without OVA injection (Ctrl). MFI = mean fluorescence intensity ( $n=3$ mice, Error bars: SD).

(B). Gating strategy for results shown in (C). Some animals were injected a second time with OVA using the same dose and route after 3 days (short interval) or 11 days (Iong interval). Seven days after the last OVA injection spleen cells were labelled with CFSE and restimulated ex vivo as indicated. FACS analysis for CD4, KJ1-26 and CFSE of spleen cells was performed to analyse the proliferation history of the DO11.10 T cells. Control mice remained without OVA injection (no OVA). Error bars: SD. Statistics only for transgenic T cells with one-way ANOVA with Tukey's test for multiple comparisons. ${ }^{\star} p<0.05,{ }^{\star \star} p<0.01,{ }^{* \star \star *} p<0.0001$. ns, not significant.

protocol clearly favoured the generation of $\mathrm{CD} 4^{+} \mathrm{KJ} 1.26^{+}$ iCTLA $-4^{+}$Foxp $^{-}$cells over CD $4^{+} \mathrm{KJ}_{1.26^{+}}$Foxp $^{+}$Treg, while $\mathrm{CD} 4^{+} \mathrm{KJ} 1.26^{+}$Foxp $^{+}$Treg expansion was more prominent with the long term interval (Figures 6C, D).

We further tested the suppressive capacity of splenic $\mathrm{T}$ cells from such treated mice in vitro. Since the absolute numbers of remaining DO11.10 cells from a single spleen were too low to isolate them for suppressor assays, we enriched the whole splenic $\mathrm{CD}^{+} \mathrm{T}$ cell population for these experiments. The results indicate that only the splenic $\mathrm{CD}^{+}{ }^{+} \mathrm{T}$ cells of short-term interval OVA-treated mice acquired significant suppressive activity as compared to control and long-term interval OVA-treated mice (Figure 6E). Of note, although the long-term protocol induced higher frequencies of Foxp $3^{+}$Treg cells (Figure 6C), this did not result in a detectable suppressive effect (Figures 6F, G). In detail, the suppressive effect was more prominent at later cell divisions $\left(3-4^{\text {th }}\right.$ generation) as 
A

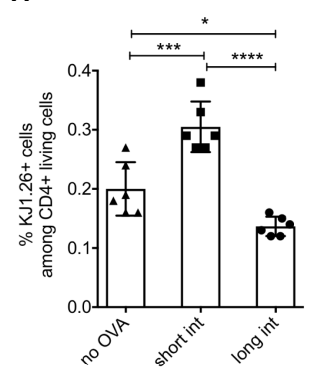

E

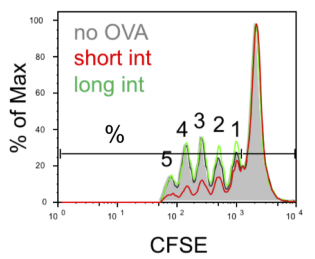

F

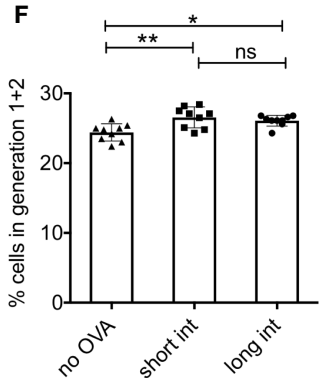

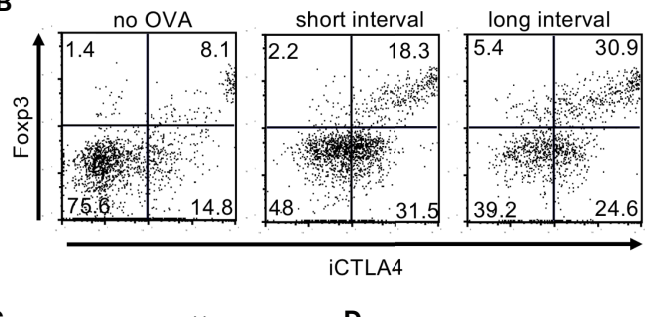
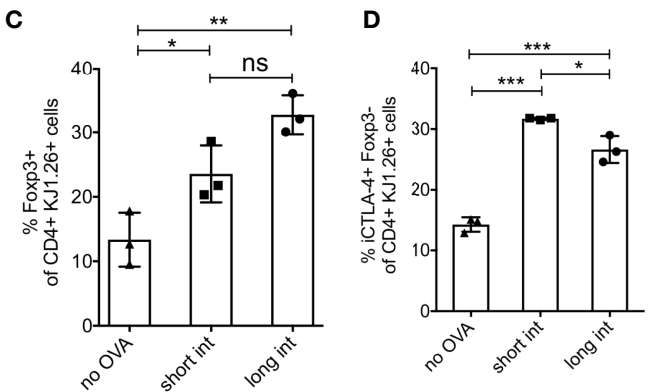

G

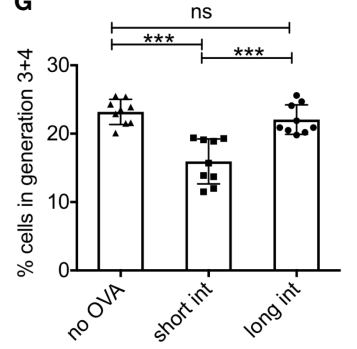

FIGURE 6 | Induction of regulatory T cells is favoured by short interval OVA injection in vivo. DO.11.10 T cells (1x107) were injected i.v. into BALB/c mice and one

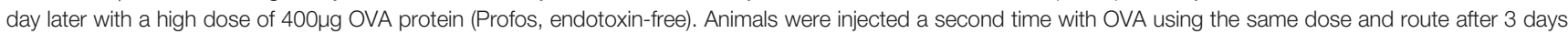
(short interval) or 11 days (long interval). (A) Five days after the last OVA injection FACS analysis was performed to determine the percentage of DO11.10 T cell recovery by KJ1-26 staining among CD4 ${ }^{+}$living spleen cells, gated as in Figure 5b but without CFSE. (B-D) Representative FACS analysis by staining CD4, KJ1-26, iCTLA-4 and Foxp3 and statistical evaluation of Treg subsets. (E-G) CD4 ${ }^{+}$splenic T cells of each mouse group were magnetically separated and tested for their suppressive capacity by culturing them with proliferating CFSE-labelled responder CD4 ${ }^{+} \mathrm{T}$ cells. (E) Example of CFSE dilution from each animal group. Numbers represent the number of cell divisions. (F, G) Summary of e showing all groups separated into early cell divisions $(1+2)$ and later divisions $(3-5)$, respectively. (Error bars: SD, Dots represent individual mice. One-way ANOVA with multiple comparisons $\left.{ }^{*} p<0.05,{ }^{* *} p<0.01,{ }^{\star \star *} p<0.005,{ }^{\star * * *} p<0.0001\right)$. ns, not significant.

compared with earlier ones (Figures 6F, G). Thus, these results suggest that only short-term interval injections of OVA promote the generation of $\mathrm{CD} 4^{+} \mathrm{KJ} 1.26^{+}$iCTLA $-4^{+}$Foxp3 ${ }^{-}$cells that are likely to account for the detectable suppressor function in our experimental settings.

\section{DISCUSSION}

Anergy can be induced in vivo by a single intravenous injection of high dose antigen and repetitive administration of antigen can induce IL-10 production in these cells $(14-16,19)$. However, the acquisition of suppressor functions after conversion of anergic non-suppressive $\mathrm{T}$ cells into Foxp $3^{-} \mathrm{IL}-10^{+}$suppressive $\mathrm{T}$ cells, so-called Tr1 cells, in vivo are still not fully understood. Furthermore, markers of anergic T cells and the converted Tr1 cells have not been studied in detail. We therefore sought to characterize the cells at different stages from anergic to IL- $10^{+}$
$\operatorname{Tr} 1$ cells and their regulatory function. Together, our data show the induction of several surface markers associated with anergy on naive $\mathrm{T}$ cells after a single high dose OVA injection and their further up-regulation during conversion to $\operatorname{Tr} 1$ cells after a second OVA injection. At the same time Tr1 cells up-regulate IL-10 as compared with anergic T cells. The functional anergic state as measured by proliferation is maintained in $\operatorname{Tr} 1$ cells independent of the time interval between two OVA injection protocols, but suppressor function required a short-term interval where CTLA-4 is still expressed by the cells.

After a single injection of high dose OVA, T cell anergy was induced, as observed by a moderate and very transient expansion of adoptively transferred ITIB.OT-II cells. After a first wave of proliferation, a rapid deletion of antigen-specific cells has been reported in experiments comparing tolerogenic versus immunogenic stimuli in vivo (38). High dose antigen injection in form of either OVA peptide or full OVA protein further led to upregulation of several markers associated with $\mathrm{T}$ cell anergy. A 
combination of the surface markers CD28 and PD-1 has been proposed to identify anergic $\mathrm{T}$ cells and to delineate them from naïve or activated T cells (28). In our experiments CD28 and PD-1 expression were slightly upregulated upon high dose antigen injection. Furthermore, a naturally occurring population of anergic $\mathrm{CD}^{+} \mathrm{T}$ cells has been described as Foxp3 ${ }^{-} \mathrm{CD} 44^{\text {high }}$ CD73 ${ }^{\text {high }}$ FR $4^{\text {high }}$ (20). In our model, Foxp3 expression was not induced in adoptively transferred OT-II cells whereas CD44, CD73 and FR4 were all upregulated upon only one high dose OVA injection. Upregulation of the memory marker CD44 in response to antigen encounter is expected whereas CD73 and FR4 have been described for Foxp $3^{+}$Tregs $(39,40)$. Although FR4 has been reported to be essential for natural Tregs maintenance, its precise function remains unclear (40). CD73 acts together with CD39 and plays an important role in regulating extracellular ATP, which is released at sites of tissue damage and inflammation (41). Adenosine, which is finally generated in this process has been shown to exhibit numerous immunoregulatory activities (42). CD73 has therefore been proposed as an additional pathway by which both classical $\mathrm{CD}_{25}{ }^{+}$Foxp $^{+}$Tregs but also CD25 ${ }^{-} \mathrm{T}$ cells can perform suppressive and anti-inflammatory functions (39). In our case, injected OT-II cells upregulated intracellular CTLA-4 and the transcription factor Egr-2, both of which have been shown to play important role in anergy induction and maintenance $(24,29,43)$.

Several analyses revealed a dominant role for the early growth response genes 2 (Egr-2) and 3 (Egr-3) for expression of the anergy-associated transcriptional program, as identified in clonal anergy and in in vivo anergy models $(8,28,29)$. The functional requirement for Egr-2 expression for $\mathrm{T}$ cell anergy has been demonstrated also in vivo (44) and Egr-2 induction was dependent on TCR-mediated NFAT signalling (45). Therefore, Egr-2 serves as one of the best markers for anergic T cells.

CTLA- 4 is required for the conversion of anergic T cells into Tr1 cells in vitro and Egr-2 is crucial for IL-27-dependent differentiation into IL- $10^{+} \operatorname{Tr} 1$ cells $(23,46,47)$ indicating that both factors prime anergic cells for conversion into $\operatorname{Tr} 1$ cells by a single antigen injection. The functional role for $\operatorname{Tr} 1$ conversion or suppression of all these different markers was not further investigated here and remains to be determined by future studies.

Alike CD28, CD25, which was upregulated shortly after the first antigen encounter, was not significantly induced at any time point after the second stimulus. This marks a clear-cut difference to the in vitro findings using immature $\mathrm{DC}$ for $\mathrm{Tr} 1$ conversion when the converted cells expressed high levels of CD25 and employed IL-2 consumption as a suppressor mechanism (23). However, impaired re-expression of CD25 in in vivo anergized $\mathrm{T}$ cells has been described previously (48). Since characteristics and mechanisms of anergy induction (especially regarding the role of CTLA-4) and anergy reversal largely differ between in vitro and in vivo models, differences in the conversion or reactivation of anergic $\mathrm{T}$ cells are also likely.

Besides surface marker expression, in our DO11.10 system, the cells showed reduced proliferative capacity, the hallmark of $\mathrm{T}$ cell anergy (3). In the OT-II system, functional anergy could not be tested due to their disappearance by unspecific deletion but may be suggested by their phenotypic characteristics and the lack of IL-10 production after the first injection (4). Our in vitro data indicated that a second antigenic stimulus has to occur within a short time span in which high CD28 and CTLA-4 expression is a prerequisite to foster the conversion of anergic $\mathrm{T}$ cells to $\mathrm{Tr} 1$ cells with suppressive capacity (23). Interestingly, the marker phenotype of $\operatorname{Tr} 1$ cells induced from both OT-II and DO11.10 cells remained quite similar after the second OVA injection, pointing out the anergic phenotype. This, however, does not conflict with the 'regulatory effector $\operatorname{Tr} 1$ phenotype' described here since IL- $10^{+}$Foxp $^{-}$Tr1 cells and even Foxp3 ${ }^{+}$Tregs have been shown to be anergic, probably to prevent the premature inhibition and shut-down of the early immune response (4).

Anergic T cells expressing both CD73 and FR4 have been shown to convert into Foxp $3^{+}$Tregs in vivo (20). In our OT-II experiments, however, $\mathrm{CD} 44^{+} \mathrm{CD} 73^{+} \mathrm{FR} 4^{+}$cells generated by a single high dose OVA injection rather converted into Foxp $3^{-}$IL- $10^{+} \mathrm{Tr} 1$ cells upon a second antigen injection within a short-time window while the frequency of classical Foxp $3^{+}$Tregs remained low. Foxp $3^{+}$Tregs can be induced in vivo by continuous application of low dose antigen by osmotic minipumps and TGF- $\beta$ from steady-state migratory DC (49). In contrast, high dose antigen application as used in our anergy model may exceed the capacity of the endogenous TGF- $\beta$ in the antigen presenting system to provide enough of this cytokine for Treg conversion, thereby blocking Treg induction and instead promoting the generation of $\operatorname{Tr} 1$ cells. In the DO11.10 system, we also observed an increase in Foxp $3^{+}$cells using the short-term protocol. This may be a characteristic of the BALB/c mouse strain, which has been shown to generate higher proportions of Foxp $3^{+}$ cells than C57BL/6 mice also in other settings such as influenza virus vaccination (50).

The key players for $\operatorname{Tr} 1$ conversion in the in vitro setting using immature DCs were CTLA-4 and CD28 (23). We could show that injection of high dose antigen leads to an upregulation of iCTLA-4 in both adoptively transferred OT-II and DO11.10 cells and that a second stimulus shortly after the first one allowed for conversion into Tr1-like cells in the OT-II setting. To test whether this conversion critically depends on CTLA-4, we aimed to perform the second OVA injection at time points when anergic cells exhibited low CTLA-4 expression. Unfortunately, this was not possible in the OT-II system since anergic T cells were rapidly deleted in this setting. In contrast, anergic DO11.10 cells seemed to be more stable in vivo allowing a longer follow-up time period. Tr1 conversion in the OT-II system was mainly determined by the secretion of IL-10. However, since the IL-10 reporter mouse ITIB was only available on C57BL/6 background, we were not able to confirm these findings in the DO11.10 system. Nonetheless, we confirmed regulatory function using suppression assays and found that only cells generated with the short-term injection protocol displayed a suppressive capacity supporting our hypothesis that CTLA-4 is crucial for this process. Of course, dependency on CTLA-4 and potentially also CD28 as well as other mechanisms such as ATP degradation and the requirement of Egr-2 need to be confirmed by further studies. These, however, were beyond the possibilities of our system here, that did not allow clearly to address the molecular mechanisms underlying our observations. 
Although anergy induction has been classically performed with CD3 simulation without costimulation, this may not reflect the in vivo situation of antigen-presenting cells. In contrast to antigen-experienced $\mathrm{T}$ cell clones, naïve $\mathrm{CD}^{+} \mathrm{T}$ cells were resistant to anergy induction in vivo and in vitro by anti-CD3/ TCR ligation in the absence of costimulation (51). This was not observed when we used immature bone marrow-derived DC for anergy induction (52). The two facts that anergy-inducing MHC II $^{\text {low }}$ immature BM-DCs express low levels of CD80 but not CD86 (53) and that CD80 shows a higher binding affinity to CTLA-4 than CD28 (54) may indicate a role for a DC/CD80 to T cell/CTLA-4 interaction. In fact, anergy induction of naïve CD $4^{+}$ $\mathrm{T}$ cells appeared to be additionally dependent on B7 costimulation-driven CTLA-4 engagement (55). The precise role and signalling mechanisms of CTLA-4 for anergy induction in naïve $\mathrm{T}$ cells is still a matter of debate (56). Earlier reports suggested that CTLA-4 signalling prevents cell cycle progression through regulation of the cyclin-dependent kinase (cdk) inhibitors p $27^{\mathrm{Kip} 1}$ and $\mathrm{p} 21^{\mathrm{Cip} 1}(24,57)$, although we found that this may not be a strict requirement (58). Here, we found a clear correlation between the acquisition of suppressor function of $\operatorname{Tr} 1$ cells and their up-regulation of CTLA-4. Whether CTLA-4 is required for conversion of anergic into Tr1 cells as observed before in vitro (23), or employed as a suppressor mechanism by controlling CD28 signaling (59) requires further investigations.

An important suppression mechanism of both Foxp $3^{+}$Tregs and $\operatorname{Tr} 1$ cells generated from anergic $\mathrm{T}$ cells in vitro is the consumption of IL-2 by the expression of a high affinity IL-2 receptor $(23,60)$. The same mechanism applied for peptideinduced tolerant cells when they were tested in suppression assays in vitro. However, suppressive capacity of the same cells in vivo depended on IL-10 production (61). These cells were predominantly $\mathrm{CD} 25^{-}$and CTLA $-4^{+}$thereby showing a similar $\operatorname{Tr} 1$ phenotype generated in our models. IL-10 deficiency has furthermore been shown to play an important role for an IL-10dependent feedback-control and host protection during infection (62-64). This implies an important role for IL-10-dependent suppression mediated by $\operatorname{Tr} 1$ cells especially in vivo. In this respect, is has been reported that a rapid in vivo expansion of IL10 -producing $\operatorname{Tr} 1$ cells by repetitive natural high dose bee venom exposure of beekeepers during beekeeper season downregulated local skin allergic responses and eventually conferred allergen tolerance (65). Therefore, it is tempting to speculate that high dose allergen challenge in short time intervals - as demonstrated here - might be the mechanistic basis to provide a fast and effective way to deliver naturally occurring $\mathrm{T}$ cell tolerance to allergens by $\operatorname{Tr} 1$ cells in nonallergic healthy humans.

\section{REFERENCES}

1. Valdor R, Macian F. Induction and Stability of the Anergic Phenotype in T Cells. Semin Immunol (2013) 25(4):313-20. doi: 10.1016/j.smim.2013.10.010

2. Huynh A, Zhang R, Turka LA. Signals and Pathways Controlling Regulatory T Cells. Immunol Rev (2014) 258(1):117-31. doi: 10.1111/imr.12148
Here we characterized a population of anergic $\mathrm{CD} 4^{+} \mathrm{T}$ cells that develops from naïve $\mathrm{T}$ cells after antigen encounter without costimulation. These cells expressed CD44, CD73, FR4, iCTLA-4 and Egr-2 and can be reactivated by a second antigenic stimulation. Upon this second stimulus within a short time interval, the cells maintained their anergic phenotype, started to secrete IL-10 (a characteristic feature of Foxp $3^{-}$Tr1 cells) and simultaneously suppressed effector cell proliferation. This may indicate a role for persisting anergic T cells as a memory cell pool for Foxp $3^{-} \operatorname{Tr} 1$ cells in vivo. The long-term protocol for the OVA injections led to persistence of the anergic state but not the acquisition of regulatory functions. A deeper understanding of the mechanisms that allow for reactivation of this memory compartment will be useful for the development of optimized vaccination protocols that may allow for prevention or suppression of autoimmune or allergic diseases.

\section{DATA AVAILABILITY STATEMENT}

The raw data supporting the conclusions of this article will be made available by the authors, without undue reservation.

\section{ETHICS STATEMENT}

The animal study was reviewed and approved by Regierung von Unterfranken, AZ 52/14.

\section{AUTHOR CONTRIBUTIONS}

AT, TS, LC, and IE performed the experiments and analysed the data. AT, AK, and ML compiled the data and wrote the manuscript. All authors contributed to the article and approved the submitted version.

\section{FUNDING}

This work was supported by the DFG grant LU851/14-1 for MBL and the Interdisciplinary Center for Clinical Research (IZKF) project A-408 for AK and MBL and AdvCSP-2 for AK. We thank Marion Heuer for her expert technical assistance on the project. This publication was supported by the Open Access Publication Fund of the University of Würzburg.

3. Jenkins MK, Chen CA, Jung G, Mueller DL, Schwartz RH. Inhibition of Antigen-Specific Proliferation of Type 1 Murine $\mathrm{T}$ Cell Clones After Stimulation With Immobilized Anti-CD3 Monoclonal Antibody. J Immunol (1990) 144(1):16-22.

4. Schwartz RH. T Cell Anergy. Annu Rev Immunol (2003) 21:305-34. doi: 10.1146/annurev.immunol.21.120601.141110 
5. Sloan-Lancaster J, Evavold BD, Allen PM. Induction of T-Cell Anergy by Altered T-Cell-Receptor Ligand on Live Antigen-Presenting Cells. Nature (1993) 363(6425):156-9. doi: 10.1038/363156a0

6. Macian F, Garcia-Cozar F, Im SH, Horton HF, Byrne MC, Rao A. Transcriptional Mechanisms Underlying Lymphocyte Tolerance. Cell (2002) 109(6):719-31. doi: 10.1016/s0092-8674(02)00767-5

7. Pape KA, Merica R, Mondino A, Khoruts A, Jenkins MK. Direct Evidence That Functionally Impaired CD4+ T Cells Persist In Vivo Following Induction of Peripheral Tolerance. J Immunol (1998) 160(10):4719-29.

8. Knoechel B, Lohr J, Zhu S, Wong L, Hu D, Ausubel L, et al. Functional and Molecular Comparison of Anergic and Regulatory T Lymphocytes. J Immunol (2006) 176(11):6473-83. doi: 10.4049/jimmunol.176.11.6473

9. Groux H, O'Garra A, Bigler M, Rouleau M, Antonenko S, de Vries JE, et al. A CD4+ T-Cell Subset Inhibits Antigen-Specific T-Cell Responses and Prevents Colitis. Nature (1997) 389(6652):737-42. doi: 10.1038/39614

10. Buer J, Lanoue A, Franzke A, Garcia C, von Boehmer H, Sarukhan A. Interleukin 10 Secretion and Impaired Effector Function of Major Histocompatibility Complex Class II-Restricted T Cells Anergized In Vivo. J Exp Med (1998) 187(2):177-83. doi: 10.1084/jem.187.2.177

11. Jooss K, Gjata B, Danos O, von Boehmer H, Sarukhan A. Regulatory Function of In Vivo Anergized CD4(+) T Cells. Proc Natl Acad Sci USA (2001) 98 (15):8738-43. doi: 10.1073/pnas.151088898151088898

12. Pletinckx K, Dohler A, Pavlovic V, Lutz MB. Role of Dendritic Cell Maturity/ Costimulation for Generation, Homeostasis, and Suppressive Activity of Regulatory T Cells. Front Immunol (2011) 2:39. doi: 10.3389/fimmu.2011.00039

13. Lutz MB, Schuler G. Immature, Semi-Mature and Fully Mature Dendritic Cells: Which Signals Induce Tolerance or Immunity? Trends Immunol (2002) 23(9):445-9. doi: 10.1016/s1471-4906(02)02281-0

14. Burkly LC, Lo D, Kanagawa O, Brinster RL, Flavell RA. T-Cell Tolerance by Clonal Anergy in Transgenic Mice With Nonlymphoid Expression of MHC Class II I-E. Nature (1989) 342(6249):564-6. doi: 10.1038/342564a0

15. Rammensee HG, Kroschewski R, Frangoulis B. Clonal Anergy Induced in Mature V Beta 6+ T Lymphocytes on Immunizing Mls-1b Mice With Mls-1a Expressing Cells. Nature (1989) 339(6225):541-4. doi: 10.1038/339541a0

16. Kawabe Y, Ochi A. Selective Anergy of V Beta 8+,CD4+ T Cells in Staphylococcus Enterotoxin B-Primed Mice. J Exp Med (1990) 172 (4):1065-70. doi: 10.1084/jem.172.4.1065

17. Rellahan BL, Jones LA, Kruisbeek AM, Fry AM, Matis LA. In Vivo Induction of Anergy in Peripheral V Beta 8+ T Cells by Staphylococcal Enterotoxin B. J Exp Med (1990) 172(4):1091-100. doi: 10.1084/jem.172.4.1091

18. Gabrysova L, Wraith DC. Antigenic Strength Controls the Generation of Antigen-Specific IL-10-Secreting T Regulatory Cells. Eur J Immunol (2010) 40 (5):1386-95. doi: 10.1002/eji.200940151

19. Gabrysova L, Nicolson KS, Streeter HB, Verhagen J, Sabatos-Peyton CA, Morgan DJ, et al. Negative Feedback Control of the Autoimmune Response Through Antigen-Induced Differentiation of IL-10-Secreting Th1 Cells. J Exp Med (2009) 206(8):1755-67. doi: 10.1084/jem.20082118

20. Kalekar LA, Schmiel SE, Nandiwada SL, Lam WY, Barsness LO, Zhang N, et al. Cd4(+) T Cell Anergy Prevents Autoimmunity and Generates Regulatory T Cell Precursors. Nat Immunol (2016) 17(3):304-14. doi: 10.1038/ni.3331

21. Kalekar LA, Mueller DL. Relationship Between CD4 Regulatory T Cells and Anergy In Vivo. J Immunol (2017) 198(7):2527-33. doi: 10.4049/jimmunol. 1602031

22. Bouabe H, Liu Y, Moser M, Bosl MR, Heesemann J. Novel Highly Sensitive IL10-beta-lactamase Reporter Mouse Reveals Cells of the Innate Immune System as a Substantial Source of IL-10 In Vivo. J Immunol (2011) 187 (6):3165-76. doi: 10.4049/jimmunol.1101477

23. Pletinckx K, Vaeth M, Schneider T, Beyersdorf N, Hunig T, Berberich-Siebelt F, et al. Immature Dendritic Cells Convert Anergic Nonregulatory T Cells Into Foxp3- Il-10+ Regulatory T Cells by Engaging CD28 and CTLA-4. Eur J Immunol (2015) 45(2):480-91. doi: 10.1002/eji.201444991

24. Greenwald RJ, Boussiotis VA, Lorsbach RB, Abbas AK, Sharpe AH. CTLA-4 Regulates Induction of Anergy In Vivo. Immunity (2001) 14(2):145-55. doi: 10.1016/S1074-7613(01)00097-8

25. Halliday N, Williams C, Kennedy A, Waters E, Pesenacker AM, Soskic B, et al. Cd86 Is a Selective Cd28 Ligand Supporting FoxP3+ Regulatory T Cell
Homeostasis in the Presence of High Levels of CTLA-4. Front Immunol (2020) 11:600000. doi: 10.3389/fimmu.2020.600000

26. Qureshi OS, Kaur S, Hou TZ, Jeffery LE, Poulter NS, Briggs Z, et al. Constitutive Clathrin-Mediated Endocytosis of CTLA-4 Persists During T Cell Activation. J Biol Chem (2012) 287(12):9429-40. doi: 10.1074/jbc. M111.304329

27. Janman D, Hinze C, Kennedy A, Halliday N, Waters E, Williams C, et al. Regulation of CTLA-4 Recycling by LRBA and Rab11. Immunology (2021). doi: $10.1111 /$ imm. 13343

28. Lechner O, Lauber J, Franzke A, Sarukhan A, von Boehmer H, Buer J. Fingerprints of Anergic T Cells. Curr Biol (2001) 11(8):587-95. doi: 10.1016/ S0960-9822(01)00160-9

29. Harris JE, Bishop KD, Phillips NE, Mordes JP, Greiner DL, Rossini AA, et al. Early Growth Response Gene-2, a Zinc-Finger Transcription Factor, is Required for Full Induction of Clonal Anergy in CD4+ T Cells. J Immunol (2004) 173(12):7331-8. doi: 10.4049/jimmunol.173.12.7331

30. Vieira PL, Christensen JR, Minaee S, O’Neill EJ, Barrat FJ, Boonstra A, et al. IL10-secreting Regulatory T Cells Do Not Express Foxp3 But Have Comparable Regulatory Function to Naturally Occurring CD4+CD25+ Regulatory T Cells. J Immunol (2004) 172(10):5986-93. doi: 10.4049/jimmunol.172.10.5986

31. Zlokarnik G, Negulescu PA, Knapp TE, Mere L, Burres N, Feng L, et al. Quantitation of Transcription and Clonal Selection of Single Living Cells With Beta-Lactamase as Reporter. Science (1998) 279(5347):84-8. doi: 10.1126/science.279.5347.84

32. Walker LSK, Sansom DM. The Emerging Role of CTLA4 as a Cell-Extrinsic Regulator of T Cell Responses. Nat Rev Immunol (2011) 11(12):852-63. doi: $10.1038 /$ nri3108

33. Thorstenson KM, Khoruts A. Generation of Anergic and Potentially Immunoregulatory CD25+CD4 T Cells In Vivo After Induction of Peripheral Tolerance With Intravenous or Oral Antigen. J Immunol (2001) 167(1):188-95. doi: 10.4049/jimmunol.167.1.188

34. Pletinckx K, Stijlemans B, Pavlovic V, Laube R, Brandl C, Kneitz S, et al. Similar Inflammatory DC Maturation Signatures Induced by TNF or Trypanosoma Brucei Antigens Instruct Default Th2-cell Responses. Eur J Immunol (2011) 41(12):3479-94. doi: 10.1002/eji.201141631

35. Blish CA, Gallay BJ, Turk GL, Kline KM, Wheat W, Fink PJ. Chronic Modulation of the TCR Repertoire in the Lymphoid Periphery. J Immunol (1999) 162(6):3131-40.

36. Bouillet P, Purton JF, Godfrey DI, Zhang LC, Coultas L, Puthalakath H, et al. BH3-Only Bcl-2 Family Member Bim Is Required for Apoptosis of Autoreactive Thymocytes. Nature (2002) 415(6874):922-6. doi: 10.1038/ 415922a

37. Hänig J, Lutz MB. Suppression of Mature Dendritic Cell Function by Regulatory T Cells In Vivo Is Abrogated by CD40 Licensing. J Immunol (2008) 180:1405-13. doi: 10.4049/jimmunol.180.3.1405

38. Fazekas de St Groth B, Smith AL, Higgins CA. T Cell Activation: In Vivo Veritas. Immunol Cell Biol (2004) 82(3):260-8. doi: 10.1111/j.0818-9641. 2004.01243.x

39. Kobie JJ, Shah PR, Yang L, Rebhahn JA, Fowell DJ, Mosmann TR. T Regulatory and Primed Uncommitted CD4 T Cells Express CD73, Which Suppresses Effector CD4 T Cells by Converting 5'-Adenosine Monophosphate to Adenosine. J Immunol (2006) 177(10):6780-6. doi: 10.4049/jimmunol. 177.10 .6780

40. Yamaguchi T, Hirota K, Nagahama K, Ohkawa K, Takahashi T, Nomura T, et al. Control of Immune Responses by Antigen-Specific Regulatory T Cells Expressing the Folate Receptor. Immunity (2007) 27(1):145-59. doi: 10.1016/ j.immuni.2007.04.017

41. Antonioli L, Pacher P, Vizi ES, Haskó G. CD39 and CD73 in Immunity and Inflammation. Trends Mol Med (2013) 19(6):355-67. doi: 10.1016/j.molmed. 2013.03.005

42. Thiel M, Caldwell CC, Sitkovsky MV. The Critical Role of Adenosine A2A Receptors in Downregulation of Inflammation and Immunity in the Pathogenesis of Infectious Diseases. Microbes Infect (2003) 5(6):515-26. doi: 10.1016/s1286-4579(03)00068-6

43. Perez VL, Van Parijs L, Biuckians A, Zheng XX, Strom TB, Abbas AK. Induction of Peripheral T Cell Tolerance In Vivo Requires CTLA-4 Engagement. Immunity (1997) 6(4):411-7. doi: 10.1016/S1074-7613(00)80284-8 
44. Zheng Y, Zha Y, Driessens G, Locke F, Gajewski TF. Transcriptional Regulator Early Growth Response Gene 2 (Egr2) is Required for T Cell Anergy In Vitro and In Vivo. J Exp Med (2012) 209(12):2157-63. doi: $10.1084 /$ jem.20120342

45. Collins S, Lutz MA, Zarek PE, Anders RA, Kersh GJ, Powell JD. Opposing Regulation of T Cell Function by Egr-1/NAB2 and Egr-2/Egr-3. Eur J Immunol (2008) 38(2):528-36. doi: 10.1002/eji.200737157

46. Iwasaki Y, Fujio K, Okamura T, Yanai A, Sumitomo S, Shoda H, et al. Egr-2 Transcription Factor Is Required for Blimp-1-Mediated Il-10 Production in IL-27-Stimulated Cd4+ T Cells. Eur J Immunol (2013) 43(4):1063-73. doi: $10.1002 /$ eji.201242942

47. Okamura T, Fujio K, Shibuya M, Sumitomo S, Shoda H, Sakaguchi S, et al. Cd4+Cd25-LAG3+ Regulatory T Cells Controlled by the Transcription Factor Egr-2. Proc Natl Acad Sci USA (2009) 106(33):13974-9. doi: 10.1073/ pnas. 0906872106

48. Tanchot C, Barber DL, Chiodetti L, Schwartz RH. Adaptive Tolerance of CD4 + T Cells In Vivo: Multiple Thresholds in Response to a Constant Level of Antigen Presentation. J Immunol (2001) 167(4):2030-9. doi: 10.4049/ jimmunol.167.4.2030

49. Azukizawa H, Döhler A, Kanazawa N, Nayak A, Lipp M, Malissen B, et al. Steady State Migratory RelB+ Langerin+ Dermal Dendritic Cells Mediate Peripheral Induction of Antigen-Specific CD4+ Cd25+ Foxp3+ Regulatory T Cells. Eur J Immunol (2011) 41(5):1420-34. doi: 10.1002/eji.201040930

50. Hornick EE, Zacharias ZR, Legge KL. Kinetics and Phenotype of the CD4 T Cell Response to Influenza Virus Infections. Front Immunol (2019) 10:2351. doi: 10.3389/fimmu.2019.02351

51. Andris F, Denanglaire S, de Mattia F, Urbain J, Leo O. Naive T Cells Are Resistant to Anergy Induction by Anti-CD3 Antibodies. J Immunol (2004) 173(5):3201-8. doi: 10.4049/jimmunol.173.5.3201

52. Lutz MB, Kukutsch NA, Menges M, Rossner S, Schuler G. Culture of Bone Marrow Cells in GM-CSF Plus High Doses of Lipopolysaccharide Generates Exclusively Immature Dendritic Cells Which Induce Alloantigen-Specific CD4 T Cell Anergy In Vitro. Eur J Immunol (2000) 30(4):1048-52. doi: 10.1002/ (SICI)1521-4141(200004)30:4<1048::AID-IMMU1048>3.0.CO;2-W

53. Lutz MB, Kukutsch N, Ogilvie AL, Rossner S, Koch F, Romani N, et al. An Advanced Culture Method for Generating Large Quantities of Highly Pure Dendritic Cells From Mouse Bone Marrow. J Immunol Methods (1999) 223 (1):77-92. doi: 10.1016/S0022-1759(98)00204-X

54. Collins AV, Brodie DW, Gilbert RJ, Iaboni A, Manso-Sancho R, Walse B, et al. The Interaction Properties of Costimulatory Molecules Revisited. Immunity (2002) 17(2):201-10. doi: 10.1016/S1074-7613(02)00362-X

55. Wells AD, Walsh MC, Bluestone JA, Turka LA. Signaling Through CD28 and CTLA-4 Controls Two Distinct Forms of T Cell Anergy. J Clin Invest (2001) 108(6):895-903. doi: 10.1172/JCI13220
56. Rudd CE, Taylor A, Schneider H. CD28 and CTLA-4 Coreceptor Expression and Signal Transduction. Immunol Rev (2009) 229(1):12-26. doi: 10.1111/ j.1600-065X.2009.00770.x

57. Brunner MC, Chambers CA, Chan FK, Hanke J, Winoto A, Allison JP. Ctla-4Mediated Inhibition of Early Events of T Cell Proliferation. J Immunol (1999) 162(10):5813-20.

58. Verdoodt B, Blazek T, Rauch P, Schuler G, Steinkasserer A, Lutz MB, et al. The Cyclin-Dependent Kinase Inhibitors p27Kip1 and p21Cip1 Are Not Essential in T Cell Anergy. Eur J Immunol (2003) 33(11):3154-63. doi: 10.1002/ eji.200323960

59. Walker LS, Sansom DM. Confusing Signals: Recent Progress in CTLA-4 Biology. Trends Immunol (2015) 36(2):63-70. doi: 10.1016/j.it.2014.12.001

60. Thornton AM, Shevach EM. CD4+CD25+ Immunoregulatory T Cells Suppress Polyclonal T Cell Activation In Vitro by Inhibiting Interleukin 2 Production. J Exp Med (1998) 188(2):287-96. doi: 10.1084/jem.188.2.287

61. Sundstedt A, O'Neill EJ, Nicolson KS, Wraith DC. Role for IL-10 in Suppression Mediated by Peptide-Induced Regulatory T Cells In Vivo. J Immunol (2003) 170(3):1240-8. doi: 10.4049/jimmunol.170.3.1240

62. Kuhn R, Lohler J, Rennick D, Rajewsky K, Muller W. Interleukin-10-Deficient Mice Develop Chronic Enterocolitis. Cell (1993) 75(2):263-74. doi: 10.1016/ 0092-8674(93)80068-P

63. Jankovic D, Kullberg MC, Feng CG, Goldszmid RS, Collazo CM, Wilson M, et al. Conventional T-bet(+)Foxp3(-) Th1 Cells Are the Major Source of HostProtective Regulatory IL-10 During Intracellular Protozoan Infection. J Exp Med (2007) 204(2):273-83. doi: 10.1084/jem.20062175

64. Anderson CF, Oukka M, Kuchroo VJ, Sacks D. Cd4(+)Cd25(-)Foxp3(-) Th1 Cells are the Source of IL-10-mediated Immune Suppression in Chronic Cutaneous Leishmaniasis. J Exp Med (2007) 204(2):285-97. doi: 10.1084/ jem.20061886

65. Meiler F, Zumkehr J, Klunker S, Ruckert B, Akdis CA, Akdis M. In Vivo Switch to IL-10-Secreting T Regulatory Cells in High Dose Allergen Exposure. J Exp Med (2008) 205(12):2887-98. doi: 10.1084/jem.20080193

Conflict of Interest: The authors declare that the research was conducted in the absence of any commercial or financial relationships that could be construed as a potential conflict of interest.

Copyright $\odot 2021$ Thomann, Schneider, Cyran, Eckert, Kerstan and Lutz. This is an open-access article distributed under the terms of the Creative Commons Attribution License (CC BY). The use, distribution or reproduction in other forums is permitted, provided the original author(s) and the copyright owner(s) are credited and that the original publication in this journal is cited, in accordance with accepted academic practice. No use, distribution or reproduction is permitted which does not comply with these terms. 